\title{
PENGEMBANGAN MEDIA PEMBELAJARAN BIOLOGI BERBASIS HYBRID LEARNING UNTUK MENINGATKAN HASIL BELAJAR SISWA PADA SMP NEGERI 6 AMBON
}

\author{
Prelly. M. J Tuapattinaya \\ Program Studi Pendidikan Biologi, FKIP Universitas Pattimura \\ Email: frelly_tuapattinaya@yahoo.co.id
}

\begin{abstract}
Abstrak: Tujuan penelitian ini adalah untuk mengembangkan media pembelajaran berbasis hybrid learning, untuk meningkatkan hasil belajar Biologi siswa kelas VIII Bilingual SMP Negeri 6 Ambon. Penelitian dan pengembangan ini menggunakan tahapan four-D model. Penelitian dan pengembangan yang dilakukan dalam tiga tahap yaitu pendefinisian (define), perancangan (design) dan pengembangan (develop). Kemudian produk pengembangan divalidasi dan dilanjutkan dengan uji coba produk untuk mengetahui keefektifan produk yang telah dikembangkan. Hasil dari penelitian dan pengembangan ini yakni produk yang berupa perangkat pembelajaran berkualifikasi valid dan layak untuk digunakan serta dapat meningkatkan hasil belajar siswa kelas VIII Bilingual yang diajarkan menggunakan materi sistem peradaran darah manusia.
\end{abstract}

\section{Kata Kunci: Pengembangan Media, Hybrid Learning, Hasil Belajar}

Belajar adalah proses yang kompleks yang terjadi pada diri setiap orang sepanjang hidupnya. Proses belajar itu terjadi karena adanya interaksi antara seseorang dengan lingkungannya. Oleh karena itu, belajar dapat terjadi kapan saja dan dimana saja. Salah satu pertanda bahwa seseorang itu telah belajar adalah adanya perubahan tingkah laku pada diri orang tersebut yang disebabkan oleh terjadinya perubahan pada tingkat pengetahuan, ketrampilan, atau sikapnya (Sardiman, 2010).

Proses belajar diselenggarakan secara formal di jenjang sekolah. Pendekatan pembelajaran, strategi pembelajaran, metode pembelajaran dan model pembelajaran yang berorientasi dengan kurikulum sekolah yang disusun dimaksudkan untuk mengarahkan perubahan pada diri siswa secara terencana, baik dalam aspek pengetahuan, ketrampilan, maupun sikap. Akhir dari kegiatan belajar mengajar di sekolah adalah hasil belajar siswa. Hasil belajar siswa dipengaruhi oleh berbagai faktor. Baik faktor internal maupun faktor eksternal.

Kegiatan belajar mengajar yang terorganisir dan menggunakan media pembelajaran yang baik dapat meningkatkan hasil belajar siswa. Hasil observasi di SMP N 6 Ambon menunjukkan bahwa belum terdapat bahan ajar IPA, motivasi belajar siswa yang cenderung rendah sebesar 58\% sehingga hasil belajar kognitif kurang optimal ditunjukkan dengan jumlah siswa yang nilai hariannya belum mencapai KKM sebanyak 10 siswa (42\%). Salah satu upaya yang dapat dilakukan agar hasil belajar siswa dapat meningkat yaitu melalui cara mengembangkan media pembelajaran berbasis model 
pembelajaran hybrid learning. Pembelajaran dengan menggunakan media berbasis model pembelajaran hybrid learning merupakan salah satu inovasi yang dapat dilakukan oleh peneliti.

Model pembelajaran hybrid learning adalah model pembelajaran yang mengkombinasikan strategi penyampaian pembelajaran menggunakan kegiatan tatap muka (face to face) dan online (forum diskusi/chatting). Melalui pembelajaran berbasis hybrid learning siswa diharapkan mampu belajar mandiri, berkelanjutan, dan berkembang sepanjang hayat sehingga belajar akan menjadi lebih efektif, lebih efisien, dan lebih menarik. Menurut Susilo (2011) terdapat berbagai keuntungan pembelajaran hybrid dibandingkan pembelajaran tatap muka biasa yakni siswa dapat lebih sukses mencapai tujuan pembelajaran dibandingkan pembelajaran tradisional, serta adanya peningkatan interaksi dan kontak antar siswa dan antara siswa dan guru.

Beberapa penelitian telah dilakukan sebelumnya terkait dengan pembelajaran berbasis hybrid learning ini. Pratiwi, dkk. (2012) melaporkan bahwa modul pembelajaran biologi berbasis hybrid learning dapat meningkatkan hasil belajar dengan persentase $66.36 \%$ dan kemampuan berpikir kritis siswa dengan peningkatan persentase $66.94 \%$. Penelitian Kurniawati (2011) melaporkan bahwa rata-rata nilai hasil belajar siswa yang mengalami pembelajaran dengan menggunakan modul pembelajaran kimia berbasis Hybrid Learning adalah 83,5 sedangkan siswa yang tidak mengalami pembelajaran yang menggunakan modul pembelajaran berbasis Hybrid Learning adalah 70,0. Berdasarkan penelitian yang telah dilakukan, maka penelitian ini berorientasi pada pengembangan media pembelajaran biologi kemudian dilakukan uji coba terbatas pada siswa kelas VIII Bilingual menggunakan model pembelajaran hybrid learning niscaya dapat meningkatkan hasil belajar siswa. Oleh karena itu, penelitian ini bertujuan untuk menghasilkan media pembelajaran biologi berbasis hybrid learning untuk meningkatkan hasil belajar siswa pada konsep sistem pernapasan siswa kelas VIII Bilingual SMP Negeri 6 Ambon.

\section{METODE PENELITIAN}

Penelitian ini merupakan penelitian pengembangan (research and development) yaitu pengembangan bahan ajar materi polusi dengan model inkuiri terbimbing yang mengadaptasi model pengembangan 4D (Thiagarajan, 1974). Penelitian dilaksanakan dalam beberapa tahapan yaitu: (1) pendefinisian (define); (2) perancangan (design); serta (3) pengembangan (develope).

Uji coba produk hasil pengembangan meliputi dua tahapan yaitu validasi (expert appraisal) dan uji kuantitatif (quatntitative testing). Uji validasi dilakukan dalam beberapa tahapan validasi untuk menguji validitas media dan isi perangkat pembelajaran. Validasi yang dilakukan pada uji validasi meliputi validasi ahli materi, validasi ahli pengembangan media pembelajaran Hybrid Learning, validasi oleh praktisi lapangan 
pengajar IPA, serta uji coba kelompok kecil. Validator pada penelitian ini terdiri dari validator internal dan validator eksternal. Validator internal yaitu Prof. Dr. F. Leiwakabessy, M. Pd. (ahli pengembangan media pembelajaran) dan P.M.J. Tuapattinaya, M.Pd. (ahli materi) sedangkan validator eksternal yaitu Dr. M. Nur Matdoan, M. Pd. (ahli pengembangan media pembelajaran) dan Dr. Th. Watuguly, M. Kes. (ahli materi). Praktisi pelaksana pembelajaran IPA di lapangan sebagai validator adalah Ellen Laimena, S. Pd. Uji kuantitatif (quatntitative testing) dilaksanakan pada kelas VIII Bilingual SMP Negeri 6 Ambon.

Data yang diperoleh dari hasil uji validasi berupa data kualitatif dan kuantitatif. Data kualitatif berupa saran dan kritik dari validator dan tanggapan siswa tentang bahan ajar pada uji coba kelompok kecil. Data kuantitatif diperoleh dari data hasil penilaian menggunakan lembar validasi. Instrumen pengumpulan data yang digunakan yaitu lembar validasi bahan ajar. Analisis data berupa analisis deskriptif untuk data hasil validasi bahan ajar dan data hasil uji coba utama untuk ranah kognitif.

\section{HASIL DAN PEMBAHASAN}

\section{Hasil Validasi}

Hasil validasi yang akan dipaparkan pada bagian ini adalah hasil analisis data penilaian media pembelajaran Hybrid Learning pada beberapa tahapan validasi. Hasil penilaian validator terhadap materi secara lengkap disajikan pada Tabel 1.

Tabel 1. Hasil Analisis Data Hasil Validasi Materi

\begin{tabular}{clccc}
\hline No & \multicolumn{1}{c}{ Validator } & $\mathrm{p}(\%)$ & Kategori & Keputusan Uji \\
\hline 1 & Eksternal & 93.75 & Sangat Baik & Tidak Revisi \\
2 & Internal & 91.25 & Sangat Baik & Tidak Revisi \\
\hline \multicolumn{4}{r}{ Tabel 1. menunjukkan bahwa hasil perhitungan persentase } & penilaian $\langle\mathrm{p}\rangle$ media
\end{tabular}

pembelajaran Hybrid Learning oleh validator ahli materi menunjukkan bahwa secara keseluruhan media pembelajaran berkategori sangat baik dan tidak perlu revisi. Hal ini dilihat dari nilai $\langle\mathrm{p}\rangle$ yang lebih dari $85 \%$. Hasil penilaian oleh validator ahli pengembangan media pembelajaran secara lengkap disajikan pada Tabel 2.

Tabel 2. Hasil Analisis Data Hasil Validasi Ahli Pengembangan Bahan Ajar

\begin{tabular}{clccc}
\hline No & \multicolumn{1}{c}{ Validator } & $\mathrm{p}(\%)$ & Kategori & Keputusan Uji \\
\hline 1 & Eksternal & 87.5 & Baik & Tidak Revisi \\
2 & Internal & 85 & Baik & Tidak Revisi \\
\hline
\end{tabular}

Tabel 2 menunjukkan bahwa hasil perhitungan persentase penilaian $\langle\mathrm{p}\rangle$ media pembelajaran Hybrid Learning oleh validator ahli pengembangan menunjukkan bahwa secara keseluruhan media pembelajaran berkategori baik dan tidak perlu revisi. Beberapa kelebihan media berbasis hybrid learning ini terlihat dari aspek pemanfaatan teknologi, komunikasi antara guru dan siswa yang tidak dibatasi ruang dan waktu serta sumber belajar yang bisa diakses kapan dan dimana saja. Suarsana dan Mahayukti (2013) menegaskan bahwa melalui e-learning pembelajaran dapat dilakukan kapan saja dan dimana saja, tidak terikat ruang dan waktu. 
Hasil penilaian oleh praktisi pelaksana pembelajaran IPA di lapangan secara keseluruhan terhadap bahan ajar dengan model pembelajaran inkuiri terbimbing dapat disajikan pada Tabel 3.

Tabel 3. Hasil Analisis Data Hasil Validasi Praktisi Pembelajaran di Lapangan

\begin{tabular}{ccccc}
\hline No & Validator & $\mathrm{p}(\%)$ & Kategori & Keputusan Uji \\
\hline 1 & Media Pembelajaran & 93.75 & Sangat Baik & Tidak Revisi \\
\hline 2 & Rencana Pembelajaran & 93.75 & Sangat Baik & Tidak Revisi \\
\hline
\end{tabular}

Tabel 3 menunjukkan bahwa secara umum media pembelajaran dan rencana pembelajaran telah layak digunakan dalam pembelajaran. Berdasarkan hasil validasi yang dilakukan oleh validator baik validator eksternal maupun internal, maka media video sistem peredaran darah berbasis model pembelajaran hybrid learning telah layak untuk digunakan dan diajarkan kepada siswa. Untuk mengembangkan pembelajaran hybrid learning yang dapat meningkatkan kognitif siswa, maka perlu kreativitas dari guru peneliti. Menurut Diki (2013) kreatifitas adalah cara membuat sesuatu atau barang yang baru selama melakukan pekerjaan. Kreatifitas yang ditunjukkan melalui pengembangan media pembelajaran ini adalah membuat media pembelajaran audiovisual berupa video peredaran darah yang berisi alat-alat peredaran darah serta proses peredaran darah yang dapat diamati oleh siswa. Gambar dalam video ini diambil dari berbagai sumber yang relevan, serta suara yang diolah sendiri oleh peneliti. Kombinasi gambar dan suara yang tepat dan diolah oleh software dapat menghasilkan media audiovisual yang bermakna dan dapat digunakan oleh siswa.

\section{Hasil Uji Kuantitatif}

Media pembelajaran Hybrid Learning diujicobakan selama proses pembelajaran. Proses pembelajaran terbagi dalam dua tahap yakni tahap tatap muka (offline) dan tahap online. Pada tahap offline peneliti memberikan tes awal kepada siswa. Tes awal berfungsi untuk menguji kemampuan awal siswa. Setelah itu, peneliti menjelaskan materi sistem peredaran darah secara umum kepada siswa, dilanjutkan dengan menjelaskan LKS. Tahap online dilakukan dengan bantuan internet. Media pembelajaran yang telah siap diunggah ke dalam software quipper school. Setelah melakukan pembelajaran online, siswa dilanjutkan dengan tes online namun tetap diawasi oleh peneliti. Berdasarkan pembelajaran baik secara offline maupun online, maka diperoleh presentasi ketuntasan KKM oleh siswa. Hasil presentasi ketuntasan KKM dapat dilihat pada Tabel 4.

Tabel 4. Presentasi Ketuntasan KKM oleh siswa

\begin{tabular}{|c|c|c|c|c|c|c|}
\hline \multirow{2}{*}{ KKM } & \multicolumn{3}{|c|}{ Tes Awal } & \multicolumn{3}{|c|}{ Tes Akhir } \\
\hline & Frekuensi & $\%$ & Ket. & Frekuensi & $\%$ & Ket. \\
\hline$\geq 80$ & 5 & $53.13 \%$ & Tuntas & 100 & $100 \%$ & Tuntas \\
\hline$<80$ & 27 & $46.88 \%$ & Belum Tuntas & 0 & $0 \%$ & Belum Tuntas \\
\hline
\end{tabular}

Hal ini menunjukkan bahwa proses pembelajaran menggunakan model pembelajaran hybrid learning membantu meningkatkan kognitif siswa, sehingga siswa dapat mengingat dan memahami materi biologi yang sulit. Hal ini dapat dipahami, karena 
melalui hybrid learning siswa dikondisikan terlebih dahulu pada pembelajaran offline, setelah itu siswa diajak untuk belajar secara online.

Kekang (2013) berpendapat bahwa pembelajaran hybrid learning mengkombinasi pembelajaran tradisional dengan pembelajaran e-learning, apabila pembelajaran dilakukan hanya secara e-learning, maka pembelajaran tersebut bukan merupakan pembelajaran yang memanusiakan. Pembelajaran Hybrid learning juga dikenal sebagai istilah Blended Learning. Galvin (2011) menambahkan bahwa Blended learning course is an effective way to teach the skill and promote an evidence-based approach to practice in this area. Oleh karena itu, selama proses serta akhir pembelajaran membuktikan bahwa model pembelajaran hybrid learning mampu meningkatkan kognitif siswa serta kondisi pembelajaran yang dialami siswa berbeda dengan biasanya.

Pada era digital ini, pembelajaran hybrid learning merupakan salah satu cara untuk membuat pembelajaran menjadi kreatif. Oleh karena siswa telah terbiasa menggunakan alat komunikasi yang memiliki software canggih, maka saat siswa dikondisikan selama pembelajaran hybrid learning siswa telah terbiasa dan tidak merasa canggung. Selain itu, siswa SMP Negeri 6 telah menggunakan quipper school, sehingga saat peneliti mengujicobakan model pembelajaran hybrid learning, maka siswa telah terbiasa dan tidak mengalami kesulitan. Model pembelajaran hybrid learning juga memberikan pengalaman yang menarik bagi siswa. Karena, selama hybrid learning dilakukan siswa mendapat pembelajaran secara offline kemudian secara online, pembelajaran offline dilakukan karena guru menjelaskan tentang LKS kepada siswa, dilanjutkan dengan pembelajaran online, dimana siswa dapat menonton video tentang sistem peredaran darah dan dilanjutkan dengan mengisi LKS tersebut, serta terdapat forum diskusi yang dapat dilakukan oleh siswa dengan sistem chatting.

Materi sistem peredaran darah merupakan salah satu materi biologi yang abstrak, sehingga untuk membuat menjadi materi yang real guru harus mengajar menggunakan bantuan. Salah satu bantuan yang digunakan adalah media audio-visual. Prastowo (2011) mengemukakan bahwa video termasuk dalam kategori bahan ajar audiovisual yang mengkombinasikan dua materi yaitu materi visual untuk merangsang indra penglihatan dan materi auditif yang bertujuan merangsang indra pendengaran. Pembelajaran melalui rangsangan melihat dan mendengar sekaligus dapat meningkatkan kognitif siswa. Berdasarkan pengalaman belajar yang telah dikemukakan, siswa belajar berdasarkan apa yang siswa dengar dan lihat. Muslich (2009) mengemukakan bahwa ketika siswa belajar melalui melalui pengalaman pendengaran maka siswa ingat $20 \%$, belajar melalui pengalaman melihat siswa akan ingat $30 \%$, apabila siswa belajar melalui pengalaman lihat dan mendengar maka siswa akan ingat 50\%. Berdasarkan pengalaman belajar tersebut, maka mealui model pembelajaran hybrid learning, hasil belajar kognitif siswa dapat berkembang dan meningkat. Selain pengalaman pembelajaran yang telah dikemukan tersebut, keberhasilan kognitif siswa juga dipengaruhi oleh pengalaman- 
pengalaman belajar yang bermakna sebelumnya, sehingga keseluruhan belajar melibatkan pemindahan konsep, mengingat, dan menerapkan pembelajaran dalam kehidupan sehari-hari siswa.

Penelitian lain yang terkait dengan pengembangan media pembelajaran dan model pembelajaran hybrid learning diantaranya adalah Pratiwi, dkk. (2012) menyimpulkan bahwa modul pembelajaran biologi berbasis hybrid learning dapat meningkatkan hasil belajar dan kemampuan berpikir kritis siswa. Daud dan Ramahdana (2015) menyimpulkan bahwa media pembelajaran berbasis e-learning dengan menggunakan joomla dan wondershare quiz creator efektif, praktis dan dapat meningkatkan hasil belajar siswa.

\section{KESIMPULAN}

Media pembelajaran berbasis model pembelajaran hybrid learning efektif dan telah layak digunakan untuk meningkatkan hasil belajar kognitif siswa Kelas VIII Bilingual SMP Negeri 6 Ambon.

\section{SARAN}

Diharapkan untuk melakukan kajian yang lebih dalam lagi mengenai model pembelajaran hybrid dan agar dapat dikembangkan modul ataupun bahan ajar yang bermodelkan hybrid agar hasil belajar siswa dapat ditingkatkan

\section{DAFTAR PUSTAKA}

Daud, F. Dan A. Rahmadana. 2015. Pengembangan Media Pembelajaran Biologi Berbasis E-Learning pada Materi Ekskresi Kelas XI IPA 3 SMAN 4 Makasar. Jurnal Bionature. Volume 16 (1); 28-36.

Diki diki. 2013. Creativity for Learning Biology in Higher Education. Lux Journal. 3 (1);1-11.

Galvin, B. 2011. A Blended Learning Course Teaching Information Literacy For Substance Use Prevention Work. Journal of Information Literacy. 5 (1): 65-88.

Kekang, H. 2013. In The Hybrid Learning Basic Formed-Correctly Guiding Future Classroom Teaching's Education Idea and teaching Concept. Workshop Proceedings in $6^{\text {th }}$ International Conference on Hybrid Learning-ICHL. Halaman $61-72$.

Kurniawati. 2011. Pengembangan Modul Pembelajaran Hybrid Learning pada Mata Pelajaran Kimia SMA Kelas X dalam Materi Hidrokarbon. Bimafika, 3, 284-291. Muslich, M. 2009. KTSP; Pembelajaran Berbasis Kompetesi dan Kontekstual. Jakarta: Bumi Aksara. 
Pratiwi, E.H., H. Suwono, N. Handayani. 2012. Pengembangan Modul Pembelajaran Biologi Berbasis Hybrid Learning untuk Meningkatkan Kemampuan Berpikir Kritis dan Hasil Belajar Siswa Kelas XI.

Prastowo, A. 2011. Panduan Kreatif Membuat Bahan Ajar Inovatif. Yogyakarta: Diva Press.

Susilo, H. 2011. Blended Learning Untuk Menyiapkan Ssiwa Hidup Di Abad 21. Makalah disajikan dalam Seminar Nasional 2011 Pengembangan Pembelajaran Berbasis Blended Learning, Jurusan Biologi FMIPA UM, Malang, 13 November. Suarsana dan Mahayukti. 2013. Pengembangan E-Modul Berorientasi Pemecahan Masalah Untuk Meningkatkan Keterampilan Berpikir Kritis Mahasiswa. Jurnal Pendidikan Indonesia, 2 (2): 264-275. 